\title{
The Use of Social Media as a Tool for Learning: Perspectives of Students in the Faculty of Education at Kuwait University
}

\author{
Waleed Alenezi \\ Kuwait University, Kuwait \\ ORCID: 0000-0001-6474-8008 \\ Thomas M. Brinthaupt \\ Middle Tennessee State University, USA \\ ORCID: 0000-0001-8927-956X
}

Received: 4 Feb 2021

Accepted: 26 Sep 2021

\begin{abstract}
The purpose of this study is to explore the use of social media by students in the Faculty of Education, University of Kuwait. The study was conducted within the context of the socio-cultural characteristics of Kuwait, and was underpinned by Alsaied's (2017) Social Media - Learning Performance model, designed for female Arab students. A volunteer sample of 35 Kuwaiti undergraduate students ( $88.6 \%$ female) was interviewed. Students reported frequently using social media informally for socialization and entertainment, but less frequently as a formal educational tool. Most of the students perceived that social media facilitated interaction with peers, interaction with faculty, engagement, and collaborative learning. However, technical difficulties, and certain negative attitudes towards women using social media, were identified. We recommend that Kuwait University needs to harness the full benefits of social media for teaching and learning and to formulate official guidelines to control the use of social media by all faculty members and students.
\end{abstract}

Keywords: social media, Kuwait, learning performance, interaction with peers, interaction with faculty, student engagement, collaborative learning

\section{INTRODUCTION}

Technology has managed to create fundamental changes in peoples' life (Sendur Atabek \& Atabek, 2020). There are many examples of technology-related applications that have become popular in the recent period, the most prominent of which is social media. Social media consists of services that allow users to generate and share online content. The use of social media also incorporates social networking, defined as services that allow users to manage relationships in online communities (Karahoca \& Yengin, 2018). Cain (2020) agrees that the positive impacts of social media must be investigated to identify their potentials and reflections on different aspects of life. Social media is an essential component of today's technologically rich higher education environment and has created conditions for the development of new educational paradigms and modalities. Research conducted in the US and Europe has concluded that the use of social media transforms students from passive receivers to active learners, through the facility to download and upload text, images, videos and links, to complete online presentations and assignments, and to join blogs, wikis, forums, and social bookmarking for the sharing of information, news, and opinions (Giannetto et al., 2013; Neier \& Zayer, 2015; Putnik et al., 2015; Zachos et al., 2018). 
Social networking may enhance the possibilities for interactions between students, teachers, and their peers (Froment et al., 2017; Ritesh \& Umar, 2018). The use of social media offers opportunities for increased engagement, promoting a deeper connection between students, educators, and course content (Dragseth, 2018; Mehdinezhad, 2011; Welch \& Bonnan-White, 2012). Collaborative learning is another potential benefit of social media, encouraging groups of students to work together, solve a problem, complete a task, or create a product, rooted in the social constructivist principle that knowledge is created by the members of a group actively interacting and sharing experiences (Junco et al., 2012; Karahoca \& Yengin, 2018). Consistent with these benefits, Chaijum (2020) argued that social media and its associated learning methods such as brainstorming can enhance teamwork skills to improve students' analysis and problem-solving skills. During the pandemic, social media platforms are used to search for prevention and educational information to reduce the effect of this virus on many aspects of society (Khamis \& Geng, 2021). Considering the challenges imposed on different societies because of the COVID-19 pandemic (Tesfamicael \& Ayalew, 2021), many educational researchers agree that this pandemic has highlighted the important role that can be played by online teaching using social media in response to the emergency lockdowns of educational institutions (e.g., Naik et al., 2021).

The benefits of social media, derived from research conducted in the US and Europe, may not be applicable in the Arab/Islamic world, specifically at Kuwait University, where the current research was conducted. Kaposi (2014) reviewed the culture and politics of Internet use among young people in Kuwait, concluding that social, cultural, and political traditions significantly shape young people's uses of the Internet. Conservative cultural and religious perspectives may be an obstacle to the use of the Internet as a learning tool in Kuwait because some Kuwaitis believe that the use of social media encourages immoral practices (Abbas \& Fadhli, 2008). Another socio-cultural characteristic of Kuwait that are relevant to the use of social media in higher education institutions include gender inequalities (Almatrouk, 2016; Al-Sabah, 2013; Buisson, 2013; Dinkha, 2018; Hamdan, 2005; Tfaily \& Samarah, 2018); government censorship of the Internet (Shiskina \& Is-saeve, 2018); and restricted rights to free expression of ideas that contradict Islamic ideology (Abbas \& Fadhi, 2008; Shiskina \& Issaeve, 2018; Nashmi et al., 2010).

\section{Value and Impact of Study}

It is important to examine social media use in Kuwait for several reasons. As it is unclear whether Kuwaiti student interest in and experiences with social media are comparable to those of students from other world regions, the present study examines the use of social media in Kuwait. Currently, there is a lack of qualitative study of the use of social media in Kuwait. The present research provides insights into the use of social media and the assessment of its effectiveness. It also examines ways that cultural practices might play a role in how Arab/Islamic students view their use of social media. Finally, Kuwait has a formal goal of integrating social media tools into pedagogical practices in education. Progress toward this goal has accelerated when the Kuwaiti Ministry of Education decided to complete the rest of the 2019-2020 academic year "via electronic means," during the COVID-19 pandemic. Moreover, the Ministry determined that "students' assessment will be on weekly basis through interaction and virtual presence at the set educational website" ("Kuwait concludes," 2020, para. 2). The results and implications of the interviewees' answers provide important information about the use and perceptions of social media in Kuwait.

\section{Theoretical Framework}

The theoretical framework that underpinned this study was the Social Media-Learning Performance (SM-LP) model proposed by Alsaied (2017). The SM-LP model was statistically validated using a structural equation model based on quantitative data collected in a cross-sectional survey administered to 283 female students at King Abdulaziz University, Jeddah, Saudi Arabia. Based only on the perceptions of female Arab students, the SM-LP model (outlined diagrammatically in Figure 1) predicted the beneficial outcomes of the use of social media in an Arab gender-segregated educational system. The enhanced interaction with peers and teachers, associated with active collaborative learning and engagement, was posited to lead ultimately to an improvement in learning performance. 
The extent to which the SM-LP model is applicable to other educational systems, outside Saudi Arabia, is currently unknown. Furthermore, the constructs of the SM-LP model do not incorporate the impacts of social media usage outside of learning performance, that have previously been identified among Kuwaiti undergraduate students (as outlined in the literature review).

\section{Social Media Use in Kuwait}

In this section, we review what is currently known about the use of social media by staff and students at Kuwait University, as well as the Kuwaiti population, and students at other higher education institutions in the Arab/Islamic world. Kuwait University, inaugurated in 1966, is Kuwait's prime public higher education institution (Murad \& Al Awadi, 2018). At the time of this study, the undergraduate population at Kuwait University consisted of 5837 students, of which the majority $(5285,90.5 \%)$ were female. Most of the population were Kuwaiti $(4276,73.3 \%)$ whereas Saudi students represented the next largest group (410, 7.0\%). Kuwait University was one of the first educational institutions in the Arab/Islamic world to embrace the use of the Internet. Al-Ansari (2006) reported that faculty members at Kuwait University used Internet resources to search for and find up-to-date information, and to communicate with their colleagues; however, the faculty members complained about the slow speed of the services, and the need to improve the infrastructure.

Kuwait University does not currently promote the use of social media in practice as a planned pedagogical aid for all students and staff. Al-Muomen et al. (2016) conducted a survey at Kuwait University to determine the factors that influenced students' information-seeking behavior; however, the use of social media as a learning tool was not identified explicitly as a major factor. The use of social media for educational purposes at Kuwait University is not mandatory, and no official guidelines have been formulated to control the use of social media by faculty members or students, similar to those proposed for use in higher education institutions in Saudi Arabia (Al-Khalifa, 2016). Although the Kuwait Ministry of Education has announced a strategic plan for education from 2005 to 2025 ("World data," 2010/2011) including the implementation of social media to enhance the Kuwaiti educational system, the impact of this strategy has not been evaluated as well as the use of social media still not in practice in Kuwait University.

The public education system in Kuwait, including Kuwait University, is gender-segregated, meaning that male and female students are required by law to attend separate classes. Previous studies conducted in Saudi Arabia have highlighted that social media is accepted by both male and female students in gender-segregated higher education institutions, where its use may stimulate collaborative learning and engagement, as well as improve communication between the faculty members and students (Al-Khalifa, 2013; Alsaied, 2017; AlShareef, 2013; Ouder \& Abousaber, 2018).

Hamade (2009) suggested that many young Kuwaitis are addicted to social media as a platform to communicate habitually with friends and family and for entertainment. The Kuwait Times ("Social media in Kuwait," 2016) reported that $72 \%$ of the Kuwaiti population used social media for more than five hours a day, but rarely for educational purposes. Based on online data published by the Statcounter Website ("Social media stats," 2021), the most common social media application used by the Kuwaiti population is Facebook (70.74\%). Facebook is primarily used informally by Arab undergraduate students as a platform to create, develop, and maintain personal relationships, rather than as a formal learning tool (Alasir et al., 2017), although some students may also use Facebook as an informal online environment to learn English (Kabilan et al., 2010). However, excessive use of Facebook may affect the academic performance of Arab students, by distracting them from their formal studies (Ouder \& Abousaber, 2018).

Al-Menayes $(2014,2015,2016)$ presented quantitative evidence to conclude that some Kuwaiti undergraduate students may suffer from social media addiction, a potential category of Internet spectrum addiction disorder (Karaiskos et al., 2010). Social media addiction comprises the core elements of addiction, including salience, mood modification, tolerance, withdrawal, conflict, and relapse, resulting in symptoms traditionally associated with substance-related addiction (Kuss \& Griffiths, 2011). 
Al-Menayes (2014) revealed that Kuwaiti undergraduate students who exhibited signs of social media addiction achieved a lower academic performance (measured by GPA) than students who were not so addicted. The lowering of the students' academic performance was associated with the excessive time spent using social media interfering with and displacing the time that the students should allocate to studying. AlMenayes recommended that future research should explore the reasons for the use of social media by Kuwaiti students using a qualitative method, providing a direction and rationale for the current study.

COVID-19 has negatively affected all sectors in the State of Kuwait, especially after the application of emergency lockdowns. Many researchers call for the use of ICTs and social media platforms to overcome these effects (Saleh, 2020). During the pandemic, Kuwaiti teachers across all levels exerted great efforts to ensure the continuity of education by making full use of all social media platforms (Alhouti, 2020).

The current study was therefore conducted in the context of the specified socio-cultural characteristics of Kuwait and other countries in the Arab/Islamic world, taking into account the concerns expressed about the use (and potential misuse) of social media by undergraduate students, as well as the proposed need for more research to identify the motivations for using social media by Kuwaiti undergraduates.

The objectives of this qualitative study were to: (1) determine the familiarity and experience of Kuwaiti students in the use of social media, (2) identify the social media applications used most frequently by Kuwaiti students, (3) explore the ease of use of social media by Kuwaiti students, (4) explore how social media is associated with the learning performance of Kuwaiti students, and (5) identify other non-educational uses of social media by Kuwaiti students.

\section{METHOD}

\section{Participants}

Qualitative data were collected by interviewing a volunteer sample consisting of 35 Kuwaiti undergraduate students between 20-22 years of age, enrolled in the Faculty of Education, between December 2016 and January 2017. Most $(31,88.6 \%)$ of the interviewed students were female, reflecting a similar gender ratio to that at the university. The interviewed students were being trained as teachers from different courses. All participants were selected from the Educational Technology course (later in the semester after they had covered most of the course content), a required course for all college of education students. One of the goals of the course is to enable the students to ultimately transmit their knowledge and skills in the use of social media.

The sample size of 35 students was assumed to achieve saturation for the purpose of generalization to theory rather than generalization to the population (Guest et al., 2006; Saunders et al., 2017). Green and Thorogood (2009) suggested that "the experience of most qualitative researchers is that, in interview studies, little that is new comes out of transcripts after you have interviewed 20 or so people" (p. 120). Mason (2010) reported that the average sample size in a total of 516 studies that used qualitative interviews as the method of data collection was 31 participants. The sample size used in the current study was therefore above the average for qualitative research.

\section{Procedure}

The students were invited to participate voluntarily in this study via an email that was sent to all students enrolled in the Educational Technology course. All participants were interviewed at the Curriculum and Instruction Department in the College of the Education. On the consent form, they read that this study pertained to the use of social media by students in the Faculty of Education, University of Kuwait, focusing on its use as a tool for learning in a gender-segregated higher education institution. To ensure participant cooperation, they were assured about the confidentiality of their responses.

A semi-structured interviewing approach was implemented. The interview questions are listed in Appendix A. The interviewer prompted students to elaborate Yes or No answers in order to elicit richer information. 
Table 1. Thematic coding template

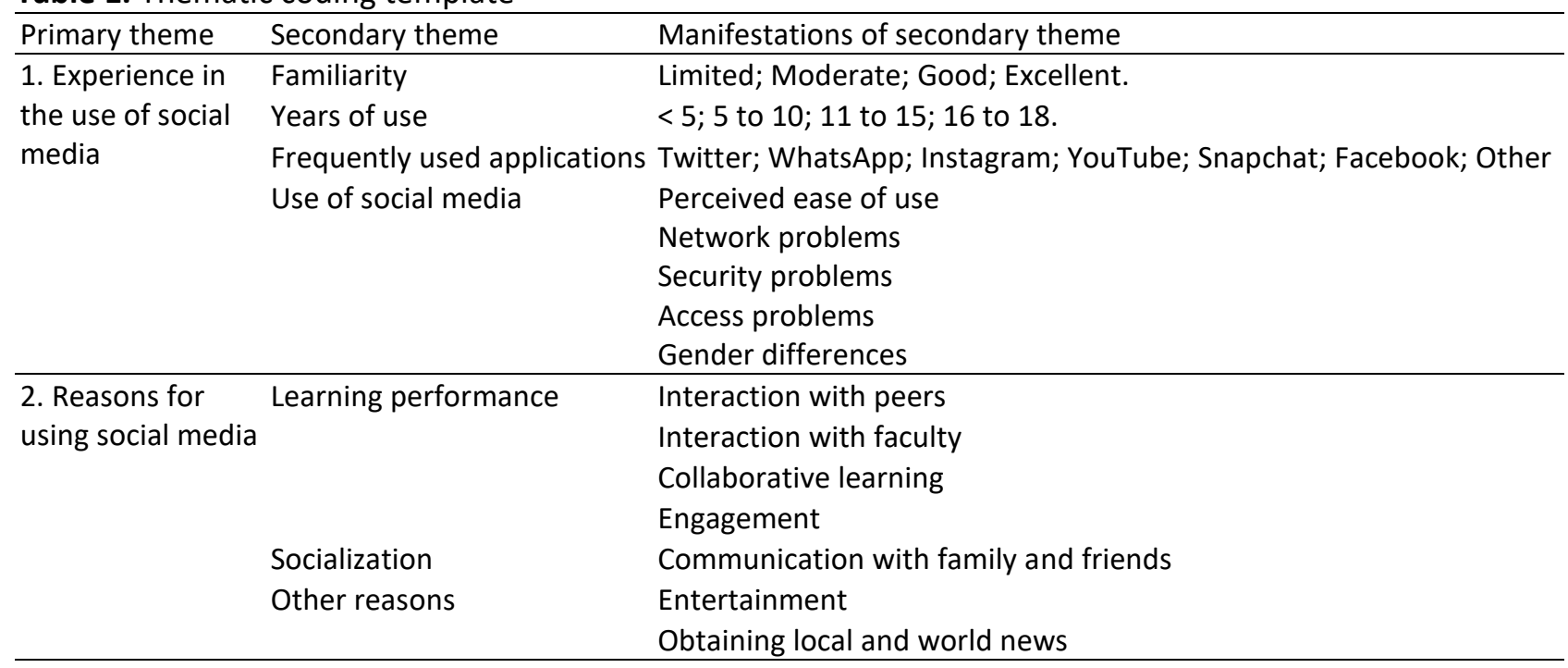

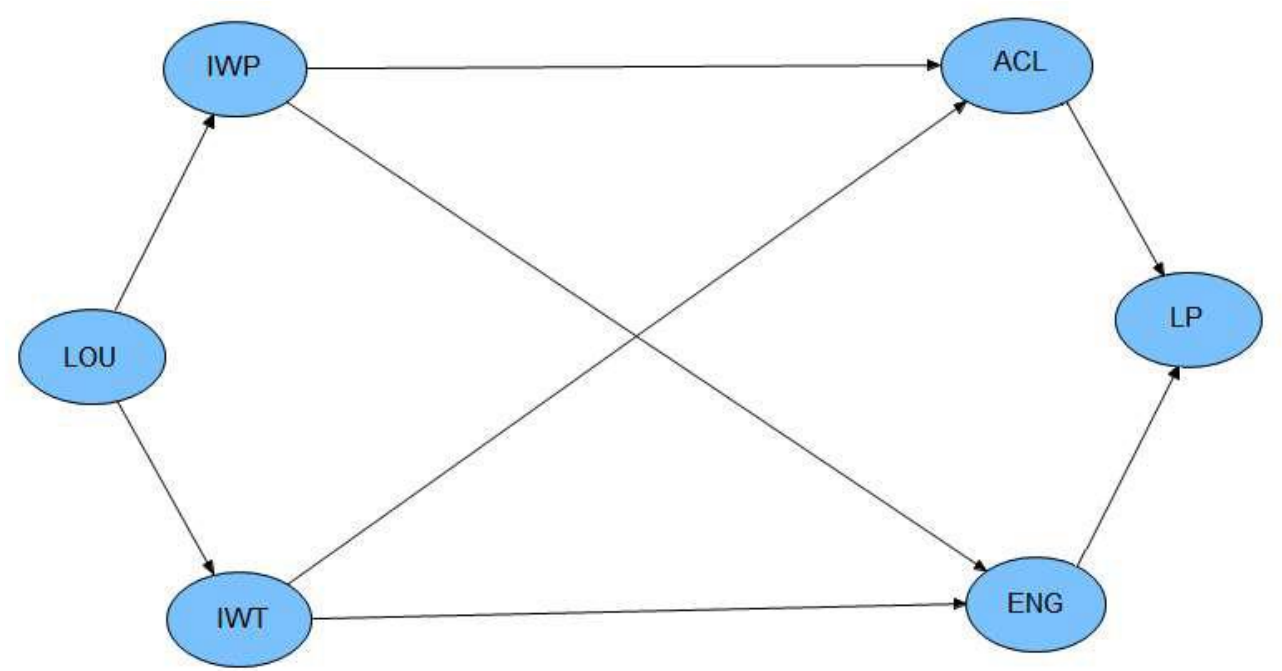

Figure 1. The social media learning performance model (adapted from Alsaied, 2017)

The 35 students were interviewed by the lead author (a male assistant professor) in a conference room of the Curriculum and Instruction Department. Participants were identified only by numbers from 1 to 35 . Male students were coded using the suffix " $M$ " (15M, 17M, 19M, and 22M). The other 31 students (numerically coded without a suffix) were female. The interviews were conducted in Arabic. The responses were audiorecorded, and a native Arabic speaker who was fluent in English translated the Arabic responses into English. Two research assistants then reviewed the interview transcripts, manually selected relevant units of information (phrases or sentences), and transcribed those into a worksheet. Template analysis was applied to code the units of information and to classify the coded information into relevant themes, based on the SM-LP model. The purpose of the template approach to thematic coding was to build on existing theory, using a list of a priori themes (Brooks et al., 2015). An initial version of the coding template was constructed using a subset of the interview responses, before defining the final thematic structure presented in Table 1.

The implementation of the coding template in Table 1 meant that the qualitative data analysis process was less time-consuming than alternative approaches to theory building (e.g., grounded theory). The template enabled the researchers to focus on key themes, underpinned by the constructs of the SM-LP model (outlined in Figure 1). The worksheets were used to aggregate the units of information into themes, as described by Meyer and Avery (2009). The data containing the quotations used to identify each theme were tabulated in order to summarize the results. 
Table 2. Experience in the use of social media

\begin{tabular}{llcc}
\hline Secondary theme & Manifestation & Frequency & $\%$ \\
\hline Familiarity & Good & 15 & 42.9 \\
& Moderate & 10 & 28.6 \\
& Excellent & 5 & 14.3 \\
& Limited & 5 & 14.3 \\
\hline Years of use & 5 to 10 & 24 & 68.6 \\
& 11 to 15 & 6 & 17.1 \\
& 16 to 18 & 3 & 8.6 \\
\hline Frequently used applications & $<5$ & 2 & 5.7 \\
& Twitter & 26 & 74.3 \\
& WhatsApp & 23 & 68.6 \\
& Instagram & 23 & 65.7 \\
& YouTube & 21 & 60.0 \\
\hline
\end{tabular}

The two primary themes were "Experience in the use of social media" and "Reasons for using social media." The secondary themes consisted of units of information categorized within each primary theme. The secondary theme "Use of social media" aligned with the same construct from the SM-LP model. The secondary theme "Learning performance" was manifested by four constructs in the SM-LP model (Interaction with peers, Interaction with faculty, Collaborative learning, and Engagement). Other reasons for using social media were not part of the SM-LP model (Communication with family and friends, Entertainment, Obtaining local and world news).

Cohen's Kappa (K) was computed to estimate the level of agreement between raters of the qualitative data (Gwet, 2014). In order to estimate $K$, two researchers independently analyzed the students' responses to two prompts: "Do you believe that social media is useful for learning purposes?" and "Explain how useful you believe that social media is for educational purposes." The two raters classified the responses into the manifestations of the secondary themes, and a small level of disagreement $(K=.729, p<.001)$ was found. The main reason for the disagreement was that one researcher classified the Yes or No responses into themes, whereas the other did not, suggesting that the responses should only be classified into themes if the students qualified their answers with detailed explanations beyond simple Yes or No answers. Although the Yes or No responses were included in the frequency data presented in the results, the Yes or No responses are not included in the thematic coding. Following the reliability check, the researchers divided the participant responses for coding.

\section{RESULTS}

\section{Theme 1: Experience in The Use of Social Media}

Table 2 presents the frequencies of the themes extracted from the interview transcripts in response to the questions (1) "How familiar are you with the use of social media?," (2) "How many years' experience do you have in using computers, the Internet, and information technology?," and (3) "Which social media applications do you use most frequently?"

The majority of the students reported that their familiarity was "Good" or "Excellent." Only a few students reported that their familiarity was "Limited" (i.e., lower than "Moderate"). The years of experience of the students ranged from less than one to 18 years. The majority of the students $(33,94.3 \%)$ reported more than five years of experience. The most frequent applications used by the majority $(\geq 21,60.0 \%)$ of students included Twitter, WhatsApp, Instagram, YouTube, and Snap-chat. Facebook was used less frequently. 
Table 3. Use of social media

\begin{tabular}{llcc}
\hline Secondary theme & Manifestation & Frequency & $\%$ \\
\hline Use of social media & Perceived ease of use & 34 & 97.1 \\
& Problems & 22 & 62.9 \\
& Network problems & 6 & 17.1 \\
& Security problems & 7 & 20.0 \\
& Access problems & 6 & 17.1 \\
& Language problems & 3 & 8.6 \\
& Gender differences ("Yes” answers) & 21 & 60.0 \\
\hline
\end{tabular}

Table 4. Use of social media: Perceived ease of use

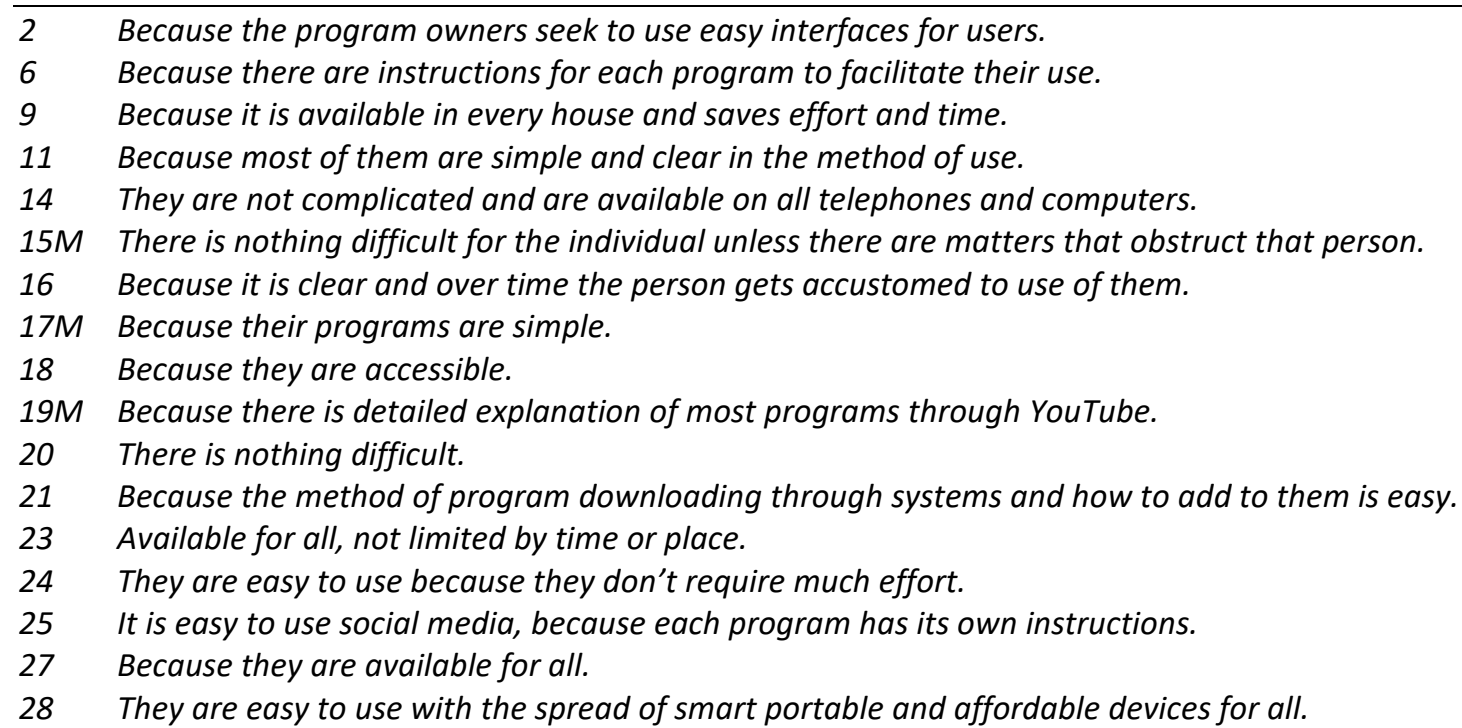

\section{Theme 2: Use of Social Media}

Table 3 presents the frequencies of the responses within the secondary themes extracted from the interview transcripts to the questions (1) "Do you find that social media is easy to use?," (2) "What particular problems do you find when using social media?," and (3) "Do you believe that using social media is more appropriate for men than for women?" Nearly all of the students perceived that social media was easy to use, although several technical problems were identified by a high proportion of students associated with the network infrastructure and attitudes toward the use of social media by men and women $(22,62.9 \%)$.

Although the question "Do you have any problems when using social media?" applied to either on or offcampus, the majority of students answered Yes because they experienced difficulties using social media on the campus network provided by Kuwait University. The reasons for these problems were classified into network, security, access, and language problems. Table $\mathbf{5}$ shows that nine students perceived that network problems acted as obstacles to using social media, reflected by slow Internet connection, failure of the system, unavailability, slow applications, and delayed download.

Table 6 shows that seven students perceived that security issues hindered the use of social media including lack of privacy, hackers, theft of accounts, distrust of technology, and exposure to offense by anonymous persons. Table $\mathbf{7}$ identifies the difficulties of using social media reported by six students including improper access (to social media applications), uploading images or videos, registration and conditions, updates of programs, and difficult settings.

Three students experienced difficulties in the use of social media classified as "Language problems" reflected by (27) "It doesn't deal with colloquial language so we always find that it corrects and doesn't accept errors," (30) "Difficult management of the programs that are not compatible with Arabic, English and French," and (32) "Don't allow change of keyboard to Arabic or change it but typing doesn't appear in Arabic." 
Table 5. Use of social media: Network problems

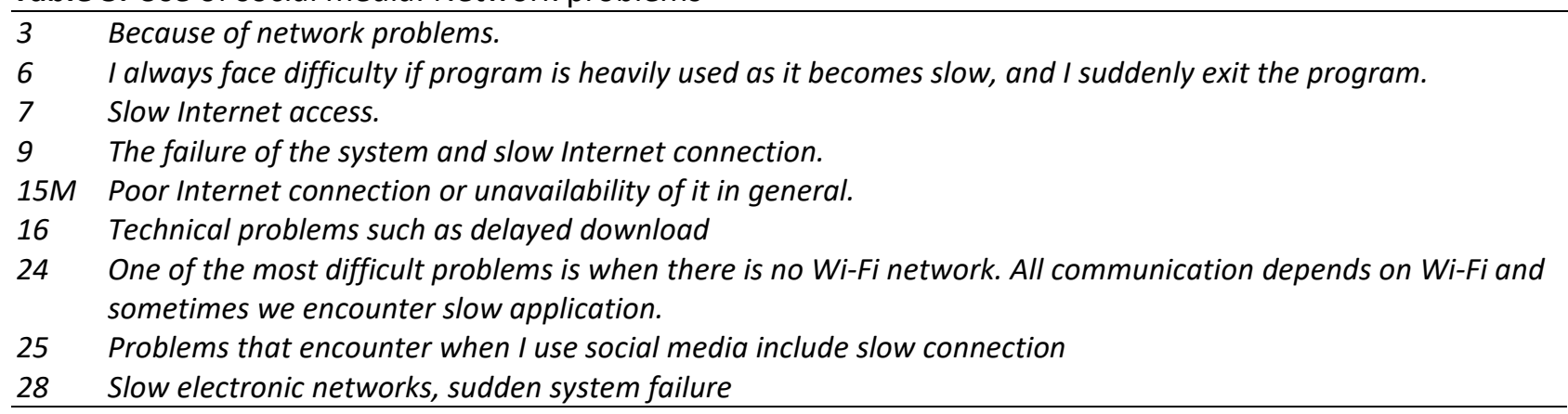

Table 6. Use of social media: Security problems

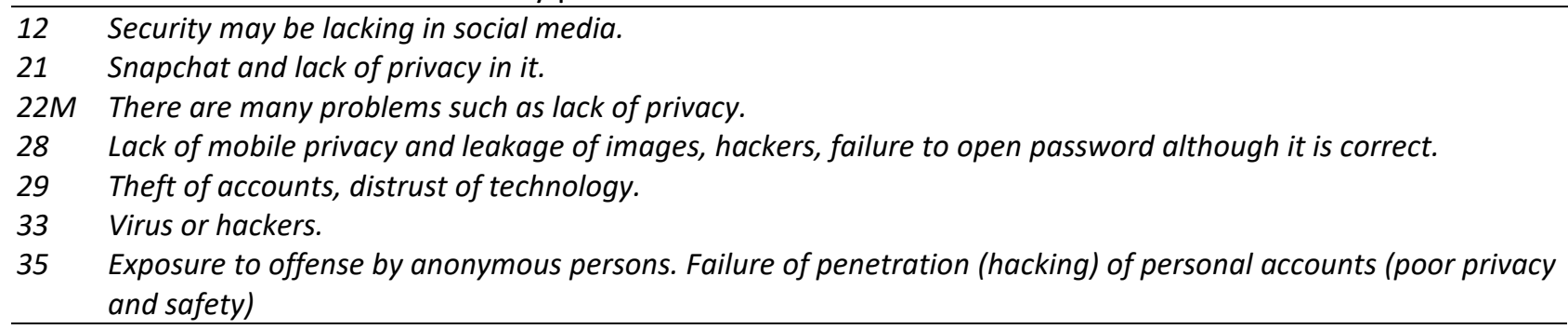

Table 7. Use of social media: Access problems

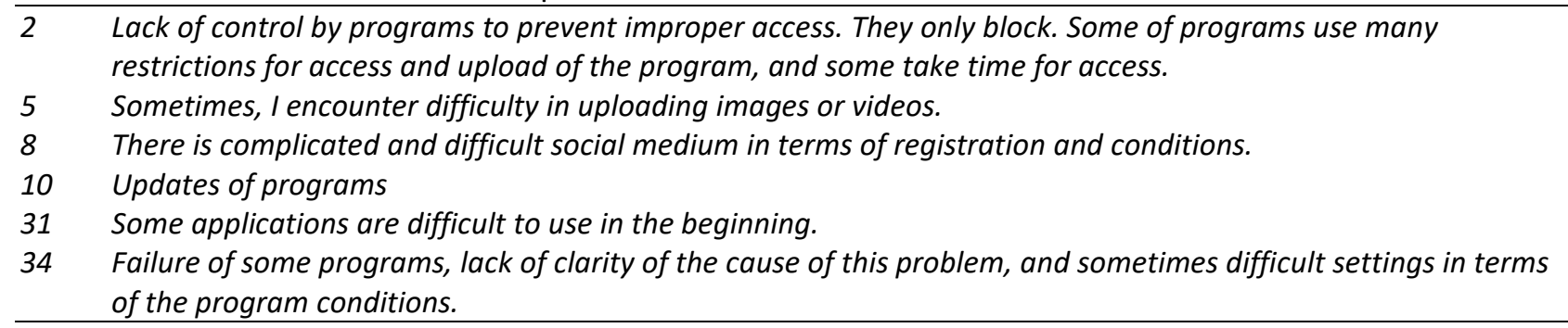

The theme "Gender differences" was identified to provide an understanding of the attitude of the students toward the issue of how gender-segregated education may influence the use of social media at Kuwait University. Six of the students $(6,17.1 \%)$ replied No to the question "Do you believe that using social media is more appropriate for men than for women?" A dichotomy of opinion was revealed, reflected by "Women are more appropriate to use social media" versus "Can be used more widely and clearly by men than by women." However, the subsequent responses in Table 8 indicated that a higher proportion of students (15, 42.9\%) perceived that using social media was not more appropriate for men than for women, reflected phrases such as all can use it; it is suitable to both genders; appropriate for men and women; and a benefit to both genders.

Table 9 presents the frequencies of the responses within the secondary themes extracted from the interview responses to the questions (1) "What are your main reasons for using social media? Explain how useful you believe that social media is for specific learning purposes." and (2) "Do you believe that, overall, the use of social media helps to improve the learning performance of students?" Social media were most frequently used for communication with family and friends $(31,88.6 \%)$ as well as entertainment $(28,80.0 \%)$. The majority of the students also perceived that social media was a useful tool to improve learning performance, including interacting with peers and faculty, collaborative learning, and engagement. The subsequent sections provide the quotations that were interpreted as evidence to identify each of these elements of learning performance.

Most of the students reported that they used social media to interact with their peers. Table 10 presents examples of eight responses emphasizing how social media facilitated interaction, communication, sharing, and connecting. 
Table 8. Use of social media: Gender differences

$5 \quad$ I don't believe that it is appropriate for both genders.

$6 \quad$ Women are more appropriate to use social media.

$19 M$ Not equal.

28 For women, not many positives will accrue from social media in the field of education and family, and learning many skills of culinary art and beautification.

30 Yes, if we want to assign an answer to our Eastern society.

34 Can be used more widely and clearly by men than by women, such as display of personal photos in applications.

2 All can use it in accordance with their needs.

$3 \quad$ I believe that it is suitable to both genders and there is no difference in use.

8 It is considered appropriate for men and women.

9 It is suitable to the parties equally and there is no difference for any of them.

11 They are equal.

13 It has become accessible for all genders.

14 The use of social media is suitable for all genders and don't differentiate them.

16 I don't think that use of social media is more appropriate for man than for women

$22 \mathrm{M}$ There is no difference between them. They are appropriate for men and women.

23 If women use social media properly and usefully, social media is useful to them.

25 No (there is no difference between men and women)

29 Both of them.

31 They are equal in use.

33 Use and benefit are same.

35 Benefit to both genders.

Table 9. Reasons for using social media

\begin{tabular}{llcc}
\hline Secondary theme & Manifestations of secondary theme & Frequency & $\%$ \\
\hline Learning performance & Interaction with peers & 23 & 65.7 \\
& Interaction with faculty & 17 & 48.6 \\
& Collaborative learning & 22 & 62.9 \\
& Engagement & 14 & 40.0 \\
\hline Socialization & Communication with family and friends & 31 & 88.6 \\
\hline Other reasons & Entertainment & 28 & 80.0 \\
& Obtaining local and world news & 7 & 20.0 \\
\hline
\end{tabular}

Table 10. Learning performance: Interaction with peers

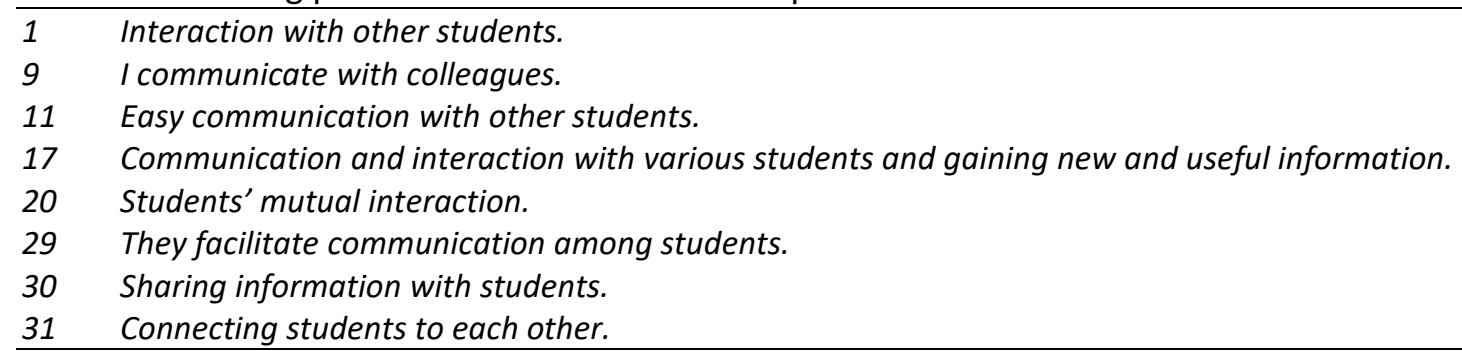

About half of the students reported that they used social media to interact with the faculty members, exemplified by the responses in Table 11. These responses included building good relations, communication, news about the university, and reminders for educational purposes.

Table 12 presents the responses of 22 students who supported the use of social media for collaborative learning, reflected by phrases such as learning with others, utilization of the experiences of others, sharing the experiences of people in general, to express our opinion and share information, and benefit from the experiences of others.

The theme "Engagement" was identified within the secondary theme "Learning Performance" by interpreting the responses of 14 students who focused on their belief that social media helped them to improve their 
Table 11. Learning performance: Interaction with faculty

\begin{tabular}{ll}
\hline 3 & Are useful in communication with university professor to answer certain questions. \\
4 & They are useful in identification of the teacher's personality \\
5 & May help in building good relations between student and teacher. \\
8 & Communication with teaching staff. \\
13 & Communication with some professors. \\
16 & News about university including apologies and other matters. \\
21 & Reminders for educational purposes and communication with teachers. \\
24 & Communication with university community. \\
29 & They facilitate communication with professors. \\
\hline
\end{tabular}

Table 12. Learning performance: Collaborative learning

1 It opens room for free education to many people of various social classes to learn new things.

3 Any person can improve his skills and information in the field of his work by following up these groups and communicating with his colleagues, and by sharing experiences easily and smoothly.

$6 \quad$ llearned creative ideas that are used in teaching.

7 To share and make benefit from teaching experiences and learning with others.

$9 \quad$ Sharing of learning experiences with others.

12 Benefits of social media include learning from the experiences of others.

13 Social media have many benefits, primarily the utilization of the experiences of others.

14 Social media are useful in sharing the experiences of people in general.

15M In my opinion, the benefit is very big in social media, including in the academic field. For example, we find in the course of technology and education means discussion and debate focused on one of those programs to be able to express our opinion and share information in colloquy of certain topic.

16 Share experience with others, make benefit from the experiences of others.

$17 M$ Transfer of experience.

18 Through learning lessons on YouTube or creation of groups through WhatsApp to facilitate solution of some materials and spread of benefit.

20 Social communication is paramount in the educational purposes. It makes it easy for many persons.

21 Social media for learning purposes are very useful for learning with others.

$22 \mathrm{M}$ Communication with others for learning purpose.

24 Making it more entertaining as information is transmitted from a person to another. Group learning is more useful.

27 Learning with others, and in the field of academic subjects.

28 They deliver the points of view, consolidate relations and build new relations.

30 Allow closed group system; that is, through these applications, experiences and opinions and shared among the members of those groups, which enhances the learner's personality.

32 Big benefit. Some of them combine teachers together or students together or both of them together in the manner that service wider category and presents more points of view and exchange of experiences.

33 Learning from students of the same specialty and making benefit from them.

35 Exchange of experiences.

27 Because they are available for all.

28 They are easy to use with the spread of smart portable and affordable devices for all.

learning performance by stimulating their connection to the learning process. Table $\mathbf{1 3}$ shows how the students' engagement was reflected using phrases such as it broadens the thinking; help us in the field of our study; calls us to pay attention; prefer the smart systems and means of communication than books; enjoy using it in learning; and fosters positive and self-learning.

The students used social media most frequently for non-educational purposes, indicated by the secondary theme "Socialization" manifested by "Communication with family, and friends." and exemplified by the nine quotations listed in Table 14. Most students stated that they used social media for "Entertainment." Table 15 presents examples of different types of entertainment reported by 11 students, including videos, reading, electronic marketing, and games. The theme with the lowest number of responses regarding the use of social media $(7,20.0 \%)$ was "Obtaining local and world news" reflected by the quotations in Table 16. 
Table 13. Learning performance: Engagement

1 Yes, it broadens the thinking of student and opens room to satisfaction of his curiosity.

4 The subject is sometimes boring but our love of thought and issues are useful to help us in the field of our study, which calls us to pay attention.

$5 \quad$ Yes, because students prefer the smart systems and means of communication than books.

6 Yes, because they develop ourselves in learning and using useful and interesting educational programs.

7 There are educational programs and sites that improve the student's learning performance.

9 It is not boring because it is common for people and easy to access.

10 Yes, Internet can be used in learning without recourse to teacher.

11 Students enjoy using it in learning.

16 It gets person out of the boredom caused by the normal academic routine and make him gain skills

25 Students become more responsible and self-reliant.

30 Fosters positive and self-learning of students.

33 Student may make benefit from the educational videos that would be useful to him in explanation of all programs.

$34 \quad$ By watching some educational videos, conducting research and collecting information.

Table 14. Social media use: Socialization

$1 \quad$ For communication with some friends whom I may find difficult to see.

$6 \quad$ I sometimes communicate with my friends.

8 The key reasons are communication with family and friends,

14 Communication and interaction with people, friends and family members in my country.

15M Communication between some friends and relatives and knowing their news regardless of where they are.

18 Communication with family and friends.

21 WhatsApp for communication with friends and family

24 Communication with relatives.

32 Social (Communication with others).

Table 15. Social media use: Entertainment

\begin{tabular}{ll}
\hline 1 & I watch videos on YouTube. \\
5 & For entertainment and reading. \\
7 & Reading of short articles, watching video. \\
8 & Spending most time in reading articles, watching video...etc. \\
14 & I use those means for entertainment. \\
$17 M$ & Reading books. \\
21 & Snapchat for entertainment. \\
23 & For entertainment \\
24 & Can integrate learning with entertainment. \\
32 & Electronic marketing. \\
34 & Spending spare time. \\
35 & Entertainment in terms of games, films and marketing. \\
\hline
\end{tabular}

Table 16. Social media use: Obtaining local and world news

2 It is the exclusive transmitter of what happens in the world, and makes us familiar with what happens

$3 \quad$ Knowledge of the world news and key developments.

$9 \quad$ Receiving of important news.

11 Review of the latest news

$15 \mathrm{M}$ Knowledge of the news around the world, whether local or international.

27 Picking political news.

\section{DISCUSSION}

The results of the qualitative analysis of the interview transcripts are first interpreted in the context of the five objectives, with reference to the literature, specifically familiarity and experience; applications; ease of 
use, learning performance; and other uses of social media. Next, we discuss the implications of the results, followed by the limitations of the study, and recommendations for future research.

The familiarity and experience of the 35 participants in the use of social media were identified. The findings are consistent with the view that undergraduate students in Kuwait are generally familiar with the use of social media, and are experienced in it use (Al-Menayes, 2014, 2015, 2016). However, there was no evidence to indicate whether or not any of the participants in the current study suffered from social media addiction. None of the students volunteered that excessive informal use of social media was a problem that interfered with their formal studies.

The most frequent use of social media by the participants appeared to be for personal reasons. Over $80 \%$ of the students used social media for communication with family and friends. This finding is consistent with the conclusion that most Kuwaitis use social media as a platform to communicate with friends and family (Hamade, 2009; "Social media in Kuwait," 2016). The participants used only a narrow range of social networking sites, dominated by Twitter, WhatsApp, Instagram, YouTube, and Snapchat. Other applications that are known to be useful in higher education, such as wikis, blogs, forums, and social bookmarking (Giannetto et al., 2013; Putnik et al., 2015) were not mentioned by any of the students.

Although Facebook is reported to be used by over $40 \%$ of the Kuwaiti population ("Kuwait National ICT," 2016), it was used by only $14 \%$ of the sample. The low frequency of use of Facebook by the female students was possible because it is primarily designed as a network for socialization. Also, it could be because of cultural and religious reasons. For example, the cultural and religious ideology of some members of Saudi society is an obstacle inhibiting the use of Facebook for socialization with men by women (Al-Sharki \& Hashim, 2016), and the two countries (Saudi and Kuwait) have the same religious culture. Not using Facebook may, however, be beneficial, because of its potential negative effects on academic performance (Abdulahi et al., 2014). Al-Sharki and Hashim reported that the most popular social media application amongst Saudi students was YouTube; however, the current study indicated that YouTube was not the most popular application among Kuwaiti students. WhatsApp was popular amongst the Kuwaiti students, mainly due to the use of WhatsApp by many faculty members to communicate with students over the University network. This app makes it easy to contact others via smartphone and may also reflect that not everyone in Kuwait has email, Twitter, and Facebook. The Central Agency for Information Technology report states that "when it comes to social platforms, WhatsApp is commonly used across all nationalities." Also, the same report demonstrates Kuwaitis are using WhatsApp more than any other apps ("Kuwait National ICT," 2016).

The results of this study indicated that the Kuwaiti participants perceived that social media was easy to use, and it may help to enhance their learning performance, through interaction with peers and faculty, collaborative learning, and engagement. This finding was consistent with previous studies conducted in Saudi Arabia concluding that social media may stimulate collaborative learning and engagement, as well as improve communication between the faculty members and students in a gender-segregated educational system (AlKhalifa, 2013; Al-Shareef, 2013; Ouder \& Abousaber, 2018).

\section{Theoretical Implications}

Although we did not directly test the SM-LP model in this study, past research based on quantitative evidence found that the positive attitudes of female Saudi students toward the use of social media in a gendersegregated higher education system helped to improve their perceived learning performance (Alsaied, 2017). The attitudes of most of the students interviewed in the current study regarding the use of social media by female students were consistent with the SM-LP. However, the benefits of using social media were marred by some students believing that social media was more appropriate for men than women, and comments suggesting that some women may be incapable of using social media. The benefits of using social media as a learning tool at Kuwait University was also marred by a high proportion of students reporting technical difficulties, which were not included as moderators in the SM-LP model. It is noteworthy that certain technical difficulties, including the slow speed of the services, and the need to improve the network infrastructure, were also reported at Kuwait University by faculty members over a decade ago (Al-Ansari, 2006). 


\section{Educational Implications}

The implications of this study are based on the recognition that Kuwait University does yet not appear to have formally implemented social media for teaching and learning by all faculty members and students. This study offers insights into how faculty members can strategically incorporate social media tools into the curriculum. Currently and while conducting this study, it has become more important to incorporate social media tools especially when the Kuwaiti Ministry of Education decided to complete the 2019-2020 academic year via distance learning.

Because this study revealed that social media was perceived by most of the students to be a familiar and effective way to improve their learning performance, the University needs to harness the full benefits of social media as a pedagogic aid and to formulate official guidelines to control the use of social media within the educational context. The current stage of development of a framework at Kuwait University to guide the formal use of social media appears to be similar to that described for universities in Saudi Arabia, specifically that "research is in the early stages of identifying which factors might constitute a framework for the successful implementation" (Al-Khalifa, 2016, p. 279). In addition, there is a real need for cooperation between Kuwait University and other international universities to find optimal ways for integrating technology such as social media in teaching in exceptional circumstances (Al-Taweel et al., 2020).

\section{Limitations and Implications for Future Research}

The small sample size ( 35 participants) meant that it was only possible to generalize the qualitative results to theory, specifically the SM-LP model (Alsaied, 2017) rather than to the target population of all Kuwaiti undergraduate students. The use of a priori themes and a template analysis underpinned by theory may have resulted in bias (Brooks et al., 2015). The reluctance of some participants to provide very detailed explanations to qualify Yes or No answers was a methodological challenge of qualitative interviewing that is commonly experienced by researchers in Arab settings (Hawamdeh \& Raigan, 2014). Furthermore, acquiescence (i.e., a tendency to agree with the questions or to only indicate a positive connotation) is a communication style that is common to some Arab respondents and may bias the results of research in Arab settings (Smith, 2004).

This study considered two primary themes, specifically "Experience in the use of social media" and "Reasons for using social media." The majority of the students were familiar and experienced with the informal use of social media for socialization and entertainment, but not necessarily as a formal educational tool. Despite technical difficulties, and certain negative attitudes toward the use of social media by women, most of the students perceived that social media were easy to use and facilitated interaction with peers, interaction with faculty, engagement, and collaborative learning in a gender-segregated educational system. However, more research is needed in order to obtain richer details than are provided in the current study, to expand the SMLP model, and to explain exactly how social media help to enhance the learning performance of students in such an educational system.

More research also needs to be conducted to evaluate the impact of the strategy proposed by the Kuwait Ministry (International Bureau of Education, 2010/2011) and thereby determine the extent to which the use of social media has enhanced the Kuwaiti educational system among the entire population of undergraduate students. This evaluation should also focus on identifying the factors that will constitute a framework for the formal implementation of social media at Kuwait University as a planned pedagogical aid. This goal became more pressing during the COVID-19 pandemic when a distance learning committee was announced and appointed by Kuwait University in May 2020 to develop new strategies and regulations for distance learning ("Kuwait adopted," 2020), especially while keeping in mind that teachers and students are not prepared for this shift in the educational system (Garbe et al., 2020). This might be attributed to the fact that the shift from the traditional method to the distance system has happened abruptly in many countries around the world (Murphy et al., 2020). Accordingly, there is a real need for developed regulations and guidelines that must be formulated within the context of the socio-cultural characteristics of the Arab/Islamic world. Consistent with the abovementioned idea, Bensaid and Brahimi (2020) noted the need for a strategic agenda to organize the work of higher education institutions during the COVID-19 crisis in GCC countries by making 
full use of e-learning techniques and social media capabilities. The framework also needs to consider local problems identified in this study, associated with the network infrastructure (including security, access, and language) as well as alleviate certain gender-specific attitudes toward social media usage.

Author contributions: All authors were involved in concept, design, collection of data, interpretation, writing, and critically revising the article. All authors approve final version of the article.

Funding: The authors received no financial support for the research and/or authorship of this article.

Declaration of interest: Authors declare no competing interest.

Data availability: Data generated or analysed during this study are available from the authors on request.

\section{REFERENCES}

Abbas, H. A., \& Fadhli, M. S. (2008). The ethical dilemmas of Internet pornography in the State of Kuwait. SIGCAS Computers and Society, 38(3), 22-23. https://doi.org/10.1145/1413872.1413877

Al-Ansari, H. (2006). Internet use by the faculty members of Kuwait University. The Electronic Library, 24(6), 791-803. https://doi.org/10.1108/02640470610714224

Alhouti, I. (2020). Education during the pandemic: The case of Kuwait. Journal of Professional Capital and Community, 5(3/4), 213-225. https://doi.org/10.1108/JPCC-06-2020-0050

Al-Khalifa, H.S. (2013). The state of social media in Saudi Arabia's higher education. International Journal of Technology and Educational Marketing, 3(1), 65-76. https://doi.org/10.4018/ijtem.2013010105

Almatrouk, L. (2016). The relationship between gender segregation in schools, self-esteem, spiritual values/religion, and peer relations in Kuwait. Near and Middle Eastern Journal of Research in Education, 2016(1), 1-26. http://dx.doi.org/10.5339/nmejre.2016.3

Al-Menayes, J. (2016). The Fear of Missing Out Scale: Validation of the Arabic version and correlation with social media addiction. International Journal of Applied Psychology, 6(2), 41-46. https://doi.org/10.5923/j.ijap.20160602.04

Al-Menayes, J. J. (2014). The relationship between mobile social media use and academic performance in university students. New Media and Mass Communication, 25, 23-29.

Al-Menayes, J. J. (2015). Dimensions of social media addiction among students in Kuwait. Psychology and Behavioral Sciences, 4(1), 23-28. https://doi.org/10.11648/j.pbs.20150401.14

Al-Muomen, N., Morris, A., \& Maynard, S. (2016). Modelling information-seeking behaviour of graduate students at Kuwait University. Journal of Documentation, 68(4), 430-459. https://doi.org/10.1108/00220411211239057

Al-Sabah, M. A. (2013). Gender and politics in Kuwait: Women and political participation in the Gulf. I. B. Tauris. https://doi.org/10.5040/9780755607914

Alsaied, H., I., K., K. (2017). Perceived effectiveness of social media as an English language learning tool. Arab World English Journal, 8(1), 79-93. https://doi.org/10.24093/awej/vol8no1.7

Al-Sharki, L., \& Hashim, K. (2016). University students' perceptions of social media as a learning tool. The Journal of Social Media in Society, 5(1), 65-88.

Al-Taweel, D., Al-Haqan, A., Bajis, D., Al-Bader, J., Al-Taweel, A. M., Al-Awadhi, A., \& Al-Awadhi, F. (2020). Multidisciplinary academic perspectives during the COVID-19 pandemic. International Journal of Health Planning and Management, 35(6), 1295-1301. https://doi.org/10.1002/hpm.3032

Bensaid, B., \& Brahimi, T. (2020). Coping with COVID-19: Higher education in the GCC countries. In A. Visvizi, M. D. Lytras, \& N. F. Aljohani (Eds.), Research and innovation forum 2020: Disruptive technologies in times of change (pp. 137-153). Springer. https://doi.org/10.1007/978-3-030-62066-0_12 
Brooks, J., McCluskey, S., Turley, E., \& King, N. (2015). The utility of template analysis in qualitative psychological research. Qualitative Research in Psychology, 12(2), 202-222. https://doi.org/10.1080/14780887.2014.955224

Buisson, J. (2013). Gender segregation in Islam: Protection or destruction? Academic Journal, 2(1), 99-121.

Cain, J. A. (2020). I'm the one: Social media, social identity, and elections. Online Journal of Communication and Media Technologies, 10(4), e202025. https://doi.org/10.30935/ojcmt/9142

Chaijum, N. (2020). Using brainstorming through social media to promote engineering students' teamwork skills. European Journal of Science and Mathematics Education, 8(4), 170-176. https://doi.org/10.30935/scimath/9555

Dinkha, J. (2018). The dichotomy of education: Public vs. private. Gender and Women's Studies, 2(1), 1-17. https://doi.org/10.31532/GendWomensStud.2.1.001

Dragseth, M. R. (2018). Building student engagement through social media. Journal of Political Science Education, 14(2018), 243-256. https://doi.org/10.1080/15512169.2018.1550421

Froment, F., Gonzalez, G., Javier, A., \& Rocio, B. M. (2017). The use of social networks as a communication tool between teachers and students: A literature review. Turkish Online Journal of Educational Technology, 16(4), 126-144.

Garbe, A., Ogurlu, U., Logan, N., \& Cook, P. (2020). COVID-19 and remote learning: Experiences of parents with children during the pandemic. American Journal of Qualitative Research, 4(3), 45-65. https://doi.org/10.29333/ajqr/8471

Giannetto, D., Chao, J., \& Fontana, A., (2013). Gamification in a social learning environment. Issues in Informing Science and Information Technology, 10, 195-207. https://doi.org/10.28945/1806

Green, J., \& Thorogood, N. (2009). Qualitative methods for health research (2nd ed.). Sage Publications.

Guest, G., Bunce, A., \& Johnson, L. (2006). How many interviews are enough? An experiment with data saturation and validity. Field Methods, 18(1), 59-82. https://doi.org/10.1177/1525822X05279903

Gwet, K. L. (2014). Handbook of inter-rater reliability: The definitive guide to measuring the extent of agreement among raters (4th ed.). Advanced Analytics, LLC.

Hamade, S. (2009). Internet addiction among university students in Kuwait. Digest of Middle East Studies, 18(2), 4-16. https://doi.org/10.1111/j.1949-3606.2009.tb01101.x

Hamdan, A. (2005) Women and education in Saudi Arabia: Challenges and achievements. International Education Journal, 6(1), 42-64. https://doi.org/10.12691/education-3-1-3

Hawamdeh, S., \& Raigangar, V. (2014). Qualitative interviewing: Methodological challenges in Arab settings. Nurse Researcher. 21(3), 27-31. https://doi.org/10.7748/nr2014.01.21.3.27.e357

Junco, R., Elavasky, M., \& Heiberger, G. (2012). Putting Twitter to the test: Assessing outcomes for student collaboration, engagement and success. British Journal of Educational Technology, 44(2), 273-287. https://doi.org/10.1111/j.1467-8535.2012.01284.x

Kabilan, M. K., Ahmad, N., \& Abidin, M. J. Z. (2010). Facebook: An online environment for learning of English in institutions of higher education? Internet and Higher Education, 13(4), 179-187. https://doi.org/10.1016/j.iheduc.2010.07.003

Kaposi, I. (2014). The culture and politics of Internet use among young people in Kuwait. Cyberpsychology: Journal of Psychosocial Research on Cyberspace, 8(3), 38-50. https://doi.org/10.5817/CP2014-3-9 
Karahoca, A., Yengin, I. (2018). Understanding the potentials of social media in collaborative learning. Encyclopedia of Information Science and Technology, 14, 7168-7180. https://doi.org/10.4018/978-15225-2255-3.ch623

Karaiskos, D., Tzavellas, E., Balta, G., \& Paparrigopoulos, T. (2010). Social network addiction: A new clinical disorder? European Psychiatry, 25(1), 855. https://doi.org/10.1016/S0924-9338(10)70846-4

Khamis, R. M., \& Geng, Y. (2021). Social media usage in health communication and its implications on public health security: A case study of COVID-19 in Zanzibar. Online Journal of Communication and Media Technologies, 11(1), e202101. https://doi.org/10.30935/ojcmt/9575

Kuss, D. J., \& Griffiths, M. D. (2011). Online social networking and addiction: A review of the psychological literature. International Journal of Environmental Research and Public Health, 8(9), 3528-3552. https://doi.org/10.3390/ijerph8093528

Kuwait adopted long-distance teaching in 2020. (2020, December 28). Kuwait Times. https://news.kuwaittimes.net/website/kuwait-adopted-long-distance-teaching-in-2020/

Kuwait concludes scholastic year (2019-2020). (2020, July 16). Kuwait News Agency. https://www.kuna.net.kw/ArticleDetails.aspx?id=2909107\&language=en

Kuwait National ICT Indicators Internet usage report. (2016). Central Agency for Information Technology, The State of Kuwait. https://www.e.gov.kw/sites/kgoArabic/Documents/OpenData/Internet\%20Module \%20report\%20English_FINAL_12-04-2017.pdf

Mason, M. (2010). Sample size and saturation in PhD studies using qualitative interviews. Forum: Qualitative Research, 11(3), 8. https://doi.org/10.17169/fqs-11.3.1428

Mehdinezhad, V. (2011). First-year students' engagement at the university. International Online Journal of Educational Sciences, 3(1), 47-66.

Meyer, D. Z. \& Avery, L. M. (2009). Excel as a qualitative data analysis tool. Field Methods, 21(1), 91-112. https://doi.org/10.1177/1525822x08323985

Murad, D., \& Al Awadhi, L. (2018). Report: The quality of education in Kuwait. The Cross Cultural Diwaniya. https://static1.squarespace.com/static/5ae5dab125bf0240808df943/t/5baca382e4966bf0037ab2b0 /1538040718718/Report+-+The+Quality+of+Education+in+Kuwait.pdf

Murphy, L., Eduljee, N. B., \& Croteau, K. (2020). College student transition to synchronous virtual classes during the COVID-19 pandemic in northeastern United States. Pedagogical Research, 5(4), 1-10. https://doi.org/10.29333/pr/8485

Naik, G. L., Deshpande, M., Shivananda, D. C., Ajey, C. P., \& Manjunath Patel, G. C. (2021). Online teaching and learning of higher education in India during COVID-19 emergency lockdown. Pedagogical Research, 6(1), 1-14. https://doi.org/10.29333/pr/9665

Nashmi, E., Cleary, J., Molleda, J., \& McAdams, M. (2010). Internet political discussions in the Arab world: A look at online forums from Kuwait, Saudi Arabia, Egypt and Jordan. The International Communication Gazette, 72(8), 719-738. https://doi.org/10.1177/1748048510380810

Neier, S., \& Zayer, L.T. (2015). Students' perceptions and experiences of social media in higher education. Journal of Marketing Education, 37(3), 133-143. https://doi.org/10.1177/0273475315583748

Ouder, M., \& Abousaber, I. (2018). A study on the impact of social media usage on student academic performance: University of Tabuk an example. American Scientific Research Journal for Engineering, Technology, and Sciences, 40(1), 77-88. 
Putnik, G., Costa, E., Alves, C., Castro, H., Varela, L., \& Shahl, V. (2015). Analysing the correlation between social network analysis measures and performance of students in social network-based engineering education. International Journal of Technology and Design Education, 26(2016), 413-437. https://doi.org/10.1007/s10798-015-9318-z

Ritesh, C., \& Umar, R. (2018). Social media in higher education: A literature review of Facebook. Education and Information Technologies, 23(2), 605-616. https://doi.org/10.1007/s10639-017-9621-2

Saleh, Y. (2020). ICT, social media and COVID-19: Evidence from informal home-based business community in Kuwait City. Journal of Enterprising Communities: People and Places in the Global Economy, 15(3), 395-413. https://doi.org/10.1108/JEC-07-2020-0131

Saunders, B., Sim, J., Kingstone, T., Bakers, S., Waterfield, J., Bartlam, B., Burroughs, H., \& Jinks, C. (2017). Saturation in qualitative research: Exploring its conceptualization and operationalization. Quality and Quantity, 52(4), 1-15. https://doi.org/10.1007/s11135-017-0574-8

Sendur Atabek, G., \& Atabek, U. (2020). Techno-cultural narrations: How did the media technologies impact social life in Turkey? Online Journal of Communication and Media Technologies, 10(4), e202026.

Shiskina, A., \& Issaeve, L. (2018). Internet censorship in Arab countries: Religious and moral aspects. Religions, 9(11), 1-14. https://doi.org/10.3390/rel9110358

Smith, P. B. (2004). Acquiescent response bias as an aspect of cultural communication style. Journal of CrossCultural Psychology, 35(1), 50-61. https://doi.org/10.1177/0022022103260380

Social media in Kuwait: A double-edged sword. (2016, July 29). Kuwait Times. https://news.kuwaittimes.net/pdf/2016/jul/30/p03.pdf

Social Media Stats in Kuwait. (2021, March). Statcounter. https://gs.statcounter.com/social-mediastats/all/kuwait

Tesfamicael, S. A., \& Ayalew, Y. (2021). Mathematics education in Ethiopia in the era of COVID-19: Boosting equitable access for all learners via opportunity to learning. Contemporary Mathematics and Science Education, 2(1), ep21005. https://doi.org/10.30935/conmaths/9680

Tfaily, F., \& Samarah, A. (2018). The effect of female gender segregation in schools on academic performance, self-confidence, and peer relations: a case of colleges and universities in Kuwait. International Journal of Education and Research, 6(3), 211-234.

Welch, B., \& Bonnan-White J. (2012). Twittering to increase student engagement in the university classroom. Knowledge Management E-Learning: An International Journal, 4(3), 325-345. https://doi.org/10.34105/j.kmel.2012.04.026

World data on education: Kuwait. (2010/2011). International Bureau of Education (7th ed). United Nations Educational, Scientific, and Culture Organization.

Zachos, G., Paraskevopoulou-Kollia E-A., \& Anagnostopoulos, I. (2018). Social media usage in higher education: A review. Education Sciences, 8(4), 1-13. https://doi.org/10.3390/educsci8040194

Correspondence: Waleed Alenezi, Kuwait University, Kuwait. E-mail: dr.waleed@ku.edu.kw 


\section{APPENDIX A}

\section{Interview Questions and Prompts}

1. How many years of experience do you have in using computers, the internet, and information technology?

2. How familiar are you with the use of social media?

3. Which social media applications do you use most frequently?

4. What are your main reasons for using social media?

5. Explain how useful you believe that social media is for specific learning purposes.

6. Do you believe that, overall, the use of social media helps to improve the learning performance of students? If "Yes" then why do you believe this? If "No" then why do you not believe this?

7. Do you find that social media is easy to use? If "Yes" then why is it easy to use? If "No" then why is it not easy to use?

8. What particular problems do you find when using social media?

9. Do you believe that using social media is more appropriate for men than for women? If "Yes" then why is it more appropriate for men? 